\title{
Gaining acceptance for anesthesia information management systems among anesthesiologists
}

\author{
David R. Sinclair, MD
}

Received: 19 February 2013/Accepted: 20 March 2013/Published online: 12 April 2013

(C) Canadian Anesthesiologists' Society 2013

\section{To the Editor,}

I read with interest the recent review article by Stabile and Cooper that identifies the lack of clinician involvement in the implementation, planning, design, and installation of anesthesia information management systems (AIMS) as a barrier to the adoption of health information technology. ${ }^{1}$ Many challenges are associated with the implementation of new AIMS in the perioperative setting, including the perception that workload will increase or autonomy will decrease. ${ }^{2}$ Even if AIMS use were mandated and early acceptance occur, the negative consequences of resistance may surface over the long term if the information system were viewed as prone to error or slow. Medical directors and anesthesiology department chiefs must actively manage the change process and gain physician acceptance for the new information system. ${ }^{3}$ Failure to gain acceptance of the AIMS may result in the unsuccessful launch of the system and huge financial losses.

The Technology Acceptance Model, the most widely accepted method of adopting information technology, focuses on interventions taken by managers to change employees' attitudes toward information technology. ${ }^{4}$ The model identifies two main factors that influence an individual's intention to use information technology, namely, the extent to which the user believes that the information technology will enhance their job performance (perceived usefulness) and require little effort (perceived ease of use). Perceived usefulness is determined by social influence and system characteristics, and perceived ease of use is

D. R. Sinclair, MD ( $\varangle)$

Department of Anesthesiology, Center for Informatics and Perioperative Medicine, University of Miami, Miami, FL, USA

e-mail: dsinclair@med.miami.edu determined by facilitating factors, individual differences, and system characteristics.

Social influence variables include the opinions about use of information technology from people who are important to the user (subjective norm) and the extent to which the user's standing among their peers will be maintained or raised (image). System characteristics are defined by the degree to which the user thinks the information technology is important to their work (job relevance), effective (output quality), able to deliver results that are easy to observe and share (result demonstrability), enjoyable (perceived enjoyment), and matches their desired level of effort (objective usability). Facilitating factors refer to the user's belief that the organization supports the information technology and has committed resources to maintain its operation (perception of external control). Individual differences are defined by the degree to which the user believes in their computer skills (computer self-efficacy), is apprehensive about using a computer (computer anxiety), and is motivated to use new technology (computer playfulness).

Managers should take well-defined steps to target the determinants of perceived usefulness and perceived ease of use in order to improve the adoption of AIMS and influence acceptance of information systems among anesthesiologists. $^{4}$

1. Delegating specific tasks, such as the customization of the AIMS or changes in business processes, and holding users accountable for the implementation of system characteristics will influence perceived usefulness through job relevance, output quality, result demonstrability, and a subjective norm. In addition, increasing physician participation during the implementation process may reduce anxiety and positively 
influence perceived ease of use through the perception of external control, perceived enjoyment, and objective usability.

2. Continually communicating support for adoption of the information system influences subjective norm and image, two important determinants of perceived usefulness. Open communication also influences perceived ease of use through reduced anxiety and perceptions of external control.

3. Using game-based training stimulates intrinsic motivation to learn, making the experience more enjoyable and sparking an interest in seeking further information. ${ }^{5}$ In contrast, traditional training methods seem to focus primarily on knowledge and skills and are less effective in conveying favourable impressions about new technology. Game-based training has a positive influence on image through determinants of perceived usefulness and computer self-efficacy, computer playfulness, and perceived enjoyment of ease of use.

4. Providing different types of organizational support through help desks, internal and external experts, offsite training, and state-of-the-art infrastructure influence perceived usefulness and perceived ease of use. A supportive culture increases job relevance, output quality, and result demonstrability of the new information technology. Through a favourable perception of external control and decreased computer anxiety, perceived ease of use is also enhanced.

Table Determinants and interventions to influence acceptance for AIMS

\begin{tabular}{|c|c|}
\hline Determinants & Interventions \\
\hline Subjective Norm & $\begin{array}{l}\text { Delegate tasks, Open communication, Peer } \\
\text { support }\end{array}$ \\
\hline Image & Open communication, Game-based training \\
\hline Job Relevance & $\begin{array}{l}\text { Delegate tasks, Organization support, Peer } \\
\text { support }\end{array}$ \\
\hline Output Quality & $\begin{array}{l}\text { Delegate tasks, Organization support, Peer } \\
\text { support }\end{array}$ \\
\hline $\begin{array}{l}\text { Result } \\
\text { Demonstrability }\end{array}$ & $\begin{array}{l}\text { Delegate tasks, Organization support, Peer } \\
\text { support }\end{array}$ \\
\hline $\begin{array}{l}\text { Perception of } \\
\text { External Control }\end{array}$ & $\begin{array}{l}\text { Delegate tasks, Open communication, } \\
\text { Organization support }\end{array}$ \\
\hline $\begin{array}{l}\text { Computer Self- } \\
\text { Efficacy }\end{array}$ & Game-based training \\
\hline Computer Anxiety & $\begin{array}{l}\text { Delegate tasks, Open communication, } \\
\text { Organization support, Peer support }\end{array}$ \\
\hline $\begin{array}{l}\text { Computer } \\
\quad \text { Playfulness }\end{array}$ & Game-based training \\
\hline Perceived Enjoyment & Delegate tasks, Game-based training \\
\hline Objective Usability & Delegate tasks \\
\hline
\end{tabular}

AIMS $=$ anesthesia information management systems
5. Fostering a culture of peer support from colleagues in the same or different organization leads to opportunities for formal and informal training, improvements in work processes, and an enhanced understanding of the information technology. Users can gain insight regarding job relevance, output quality, result demonstrability, subjective norm, and image, increasing the perceived usefulness of the system. By reducing computer anxiety, peer support may also enhance perceived ease of use.

Acceptance for AIMS can be achieved among anesthesiologists by using interventions that influence their purpose for adopting new information technology (see Table). Multiple steps can be used to increase the chances for widespread acceptance of AIMS.

Funding sources None.

Commercial or non-commercial affiliations None.

Consultancies None.

Competing interests None declared.

\section{References}

1. Stabile M, Cooper L. Review article: The evolving role of information technology in perioperative patient safety. Can J Anesth 2013; 60: 119-26.

2. Kendler $J$, Wiklund $M$. Ensuring usability through human factors engineering. In: J. Stonemetz J, Ruskin K (Eds). Anesthesia Informatics. London: Springer-Verlag; 2008: 77.

3. Pearlson KE, Saunders CS. Managing and Using Information Systems: A Strategic Approach, $4^{\text {th }}$ ed. Hoboken, New Jersey: John Wiley \& Sons, Inc.; 2010: 125-6.

4. Venkatesh V, Bala $H$. Technology Acceptance Model 3 and a research agenda on interventions. Decision Sciences 2008; 39: 273-315.

5. Venkatesh V. Creation of favorable user perceptions: exploring the role of intrinsic motivation. MIS Quarterly 1999; 23: 239-60.

\section{Reply}

We appreciate Dr. Sinclair's informative comments regarding interventions that may lead to the acceptance of AIMS implementation and the introduction of the Technology Acceptance Model into anesthesiology literature.

The focus of our manuscript is on how health information technology, and specifically AIMS, can enhance perioperative patient safety, and we agree that the Technology Acceptance Model (TAM) may indeed be a way to achieve this goal. Perceived usefulness and perceived ease of use are important determinants of user acceptance and 
successful AIMS implementation, as they may help reduce anxiety and improve output quality. ${ }^{1}$ Increasing physician involvement in the implementation, planning, and design of the system can reduce criticisms of AIMS relating to user discomfort during short or emergency procedures or the physical placement of the system. ${ }^{2}$

Quality output has helped enhance patient safety, for example, in one study, compliance with beta-blocker documentation improved from $61-95 \%$, and in another study, ongoing education and motivation facilitated a $21 \%$ reduction in drug administration errors and an $81 \%$ improvement in overall documentation compliance. ${ }^{3,4}$ Both studies present successful use of interventions found in the TAM to enhance patient safety.

The TAM has been tested in pediatrics. Little weight was given to ease of use, but usefulness and job relevance were shown to be primary factors in the acceptance of information technology, confirming at least part of the role of the TAM in medicine. ${ }^{5}$ Perhaps it is time to consider adopting such a formalized model when beginning the implementation and training process for AIMS, a step that could help improve patient safety in anesthesia.

\section{Funding sources None.}

Commercial or non-commercial affiliations Lebron Cooper is a co-founder and owner of Board Stiff, Inc, and Michael Stabile is a co-founder and has financial interest in Safer Sleep, Inc.
Consultancies L. Cooper - PharMEDium Services, LLC.

Competing interests None declared.

\section{References}

1. Venkatesh V, Bala $H$. Technology Acceptance Model 3 and a research agenda on interventions. Decision Sciences 2008; 39: 273-315.

2. Jin HS, Kim MH, Lee SY, Jeong HY, Choi SJ, Lee HW. A survey of user acceptance of electronic patient anesthesia records. Korean J Anesthesiol 2012; 62: 350-7.

3. Nair BG, Peterson GN, Newman SF, Wu WY, Kolios-Morris V, Schwid HA. Improving documentation of a beta-blocker quality measure through an anesthesia information management system and real-time notification of documentation errors. Jt Comm J Qual Patient Saf 2012; 38: 283-8.

4. Merry AF, Webster CS, Hannam J, et al. Multimodal system designed to reduce error in recording and administration of drugs in anaesthesia: prospective randomised clinical evaluation. BMJ 2011; 343: d5543.

5. Chismar WG, Wiley-Patton S. Test of the technology acceptance model for the internet in pediatrics. Proc AMIA Symp 2002; 155-9.

Lebron Cooper MD

Department of Anesthesiology, University of Miami Miller School of Medicine, Miami, FL, USA

Michael Stabile MD

Anesthesia Medical Group, PC Nashville, TN, USA 